\title{
Propriedades físicas e mecânicas do concreto permeável com agregados de resíduos de isolador elétrico de porcelana
}

\author{
Physical and mechanical properties of permeable concrete with aggregates of porcelain electrical \\ insulator residues
}

Propiedades físicas y mecánicas del hormigón permeable con áridos de porcelana Residuos de aislantes eléctricos

\section{Resumo}

O presente trabalho tem por objetivo estudar a influência do emprego dos resíduos de isoladores elétricos de porcelana nas propriedades do concreto permeável. Nos últimos anos diversas pesquisas têm sido desenvolvidas com o objetivo a diminuir os impactos ambientais dos rejeitos industriais, ajustando sistemas de modo que os rejeitos de um processo produtivo possam ser utilizados como matéria-prima para a produção de outros produtos. As companhias produtoras de energia elétrica, produz um passivo anual estimado em 25.000 ton./ano de isoladores elétricos de porcelana, decorrentes da reposição de peças defasadas e do controle de qualidade industrial, e atualmente não possui um procedimento disseminado em relação a reutilização desta cerâmica, sendo muitas vezes descartados de forma inadequada no meio ambiente. Especificamente, o setor da construção civil se apresenta como um setor que pode incorporar esses resíduos de isoladores elétricos de porcelana a sua produção. Os concretos foram ensaiados quanto à resistência à compressão nas idades de 14 e 28 dias, sendo as respectivas porcentagens de substituição do volume do agregado graúdo convencional por resíduos de isoladores elétricos de porcelana de $10 \%$ e $30 \%$. Os resultados mostram que a resistência à compressão aumentou com o aumento da porcentagem de resíduo de isoladores, o material em estudo apresentou um coeficiente de permeabilidade que atende como muito baixo grau de permeabilidade e o índice de vazios não apresentou características dos concretos permeáveis. As amostras produzidas não atenderam ao requisito normativo (NBR 16416- tabela 8) de resistência à compressão de 20-35 MPa.

Palavras-chave: Concreto permeável; Isoladores de porcelana; Resistência a compressão; Resíduos.

\section{Abstract}

The present work aims to study the influence of the use of waste porcelain electrical insulators on the properties of permeable concrete. In recent years, several researches have been developed with the objective of reducing the environmental impacts of industrial waste, adjusting systems so that the waste from a production process can be used as raw material for the production of other products. The electric energy producing companies produce an estimated 
annual liability of 25,000 ton / year of porcelain electrical insulators, resulting from the replacement of outdated parts and industrial quality control, and currently do not have a disseminated procedure regarding the reuse of this ceramic, often being improperly discarded in the environment. Specifically, the civil construction sector presents itself as a sector that can incorporate these waste porcelain electrical insulators into its production. The concretes were tested for compressive strength at the ages of 14 and 28 days, with the respective percentages of replacing the volume of conventional coarse aggregate with $10 \%$ and $30 \%$ porcelain electrical insulator waste. The results show that the compressive strength increased with the increase in the percentage of waste insulators, the material under study resented a permeability coefficient that meets a very low degree of permeability and the void index did not present characteristics of permeable concretes. The samples produced did not meet the normative requirement (NBR 16416table 8) of compressive strength of 20-35 MPa.

Keywords: Permeable concrete; Porcelain isolators; Compressive strength; Residue.

\begin{abstract}
Resumen
El presente trabajo tiene como objetivo estudiar la influencia del uso de aislantes eléctricos de desecho de porcelana sobre las propiedades del hormigón permeable. En los últimos años se han desarrollado varias investigaciones con el objetivo de reducir los impactos ambientales de los residuos industriales, ajustando los sistemas para que los relaves de un proceso productivo se puedan utilizar como materia prima para la elaboración de otros productos. Las empresas que producen electricidad, producen un pasivo anual estimado en 25.000 toneladas / año de aisladores sistemas eléctricos de porcelana, resultado de la sustitución de piezas obsoletas y la calidad industrial, y actualmente no cuenta con un procedimiento generalizado en con respecto a la reutilización de esta cerámica, siendo a menudo descartada en un inadecuado en el medio ambiente. En concreto, el sector de la construcción civil se presenta como un sector que puede incorporar estos residuos de aislantes eléctricos producción de porcelana. Los hormigones fueron probados para resistencia a compresión a los 14 y 28 días, con los respectivos porcentajes de Reemplazo del volumen de agregado grueso convencional con aislantes de residuos. Electrodomésticos de porcelana del 10\% y $30 \%$. Los resultados muestran que la resistencia a la compresión aumentó con el incremento en el porcentaje de residuos aislantes, el material en estudio presentó un coeficiente de permeabilidad que sirve como muy bajo grado de permeabilidad y el índice de vacíos no presentó características de hormigones permeables. Las muestras producidas no cumplieron con el requisito normativo (NBR 16416-tabla 8) de resistencia a la compresión de 20-35 MPa.
\end{abstract}

Palabras clave: Hormigón permeable; Aislantes de porcelana; Resistencia a la compresión; Desperdicio.

\title{
1. Introdução
}

Os problemas ambientais adquiriram destaque no século $\mathrm{XX}$, devido ao aumento dos impactos da poluição, do crescimento dos danos ambientais, da ampliação dos usos dos recursos naturais e das consequências da ação antrópica no meio ambiente. Os impactos dos danos ao meio ambiente excederam o domínio local, estendendo- se em escala global (Carvalho \& Aquino, 2017).

Assim, profissionais de múltiplas áreas são instigados a diminuir os impactos ambientais de modo que os rejeitos de um processo produtivo possam ser utilizados como matéria-prima para a produção de outros subprodutos. Especificamente, o setor da construção civil gera grandes impactos no meio ambiente, tanto pelo emprego dos recursos naturais e pela alteração da paisagem, quanto pela geração de vultuosos volumes de resíduos, provocando alerta aos governos e organizações não governamentais.

Além disso, as companhias produtoras de energia elétrica, principalmente a hidráulica também produz um passivo anual estimado em 25.000 ton./ano de isoladores elétricos de porcelana, decorrentes da reposição de peças defasadas e do controle de qualidade industrial, e atualmente não possui um procedimento disseminado em relação a reutilização desta cerâmica, sendo frequente o descarte destes no meio ambiente (Ferrão \& Costa, 2010).

Outro problema enfrentado pelos municípios brasileiros são as inundações bruscas. A ocorrência com o maior número de edificações atingidas por inundações bruscas desabrigou ou desalojou 777.546 pessoas no Brasil. Um dos fatores determinantes para ocorrência desses episódios são as intervenções diretas na permeabilidade da água no solo, como as extensas avenidas asfaltadas e áreas cimentadas, ou obstáculos ao escoamento superficial da água, como sistemas de drenagem deficitários. Esses elementos, acrescidos das chuvas, podem causar alagamentos, que geram grandes transtornos para o dia a 
dia de uma cidade. Nesse contexto, pelo número cada vez mais alto de casos de enchentes, o concreto permeável é um tipo de material que pode auxiliar na redução desse índice, uma vez que ele permite uma taxa alta de percolação de água para o solo.

De acordo com Li (2009), o estudo que envolve concreto permeável já existe há mais de 150 anos, porém só começou a ganhar força há cerca de 20 anos. Pelo fato de ser um material bastante interessante para pavimentos que não sofrem cargas elevadas, este material tornou-se um objeto de estudo de muitas pesquisas, uma vez que apresentou um bom desempenho e durabilidade quando empregado em revestimento de pavimentos em áreas de veículos leves e circulação de pessoas, o que, coligado à sua capacidade de drenagem possibilita o seu emprego como equipamento urbano de mitigação dos níveis de impermeabilização intensificado pela urbanização das cidades. Uma vez evidenciada a vantagem do concreto permeável, quando analisados os fatores relacionados à permeabilidade do solo, ele pode tornar-se ainda mais vantajoso, caso faça uso de resíduos sólidos (Cardoso, Shimosaka, Filho \& Paulazzi, 2017).

Botelho e Aguado (2020) investigou que os corpos de prova apresentaram resistências abaixo de 10 MPa aos 28 dias. Porém, estão dentro da normalidade mencionada pela ACI 522R:06 (2006), com concretos permeáveis variando de 2,8 Mpa a $28 \mathrm{Mpa}$. Em relação aos ensaios de permeabilidade, notou se que o concreto permeável atingiu os aspectos esperados, percolando com êxito a água precipitada em curto período.

Milhomem, da Silva e Costa (2018) investigou a influência do resíduo de isolador de porcelana na resistência a compressão do concreto permeável. Analisando os resultados, percebeu que houve um aumento de aproximadamente 10,6\% ao correlacionar o traço de referência nas idades de 7 e 28 dias. Com teor de substituição de $25 \%$, o acréscimo de resistência foi de $19,7 \%$ em relação às misturas com mesmas idades e para as misturas contendo $50 \%$ de substituição o aumento chegou a 26,87\%. Dessa forma, ocorreu uma melhoria contínua da resistência a compressão conforme a idade e o teor de porcelana adicionado, justificando a atividade pozolânica presente nesse resíduo. Entretanto, quando comparado com o traço de referência, as misturas com idade de 28 dias e com substituição de $50 \%$ de resíduo a média das resistências foram superiores. Comparando também à resistência a compressão do traço com 50\% de resíduo de isolador de porcelana com a resistência média dos corpos de prova de referência aos 28 dias, percebe-se que o aumento não foi tão expressivo, apenas 6\%. Realizando o mesmo comparativo com o traço de $25 \%$ de resíduo de isolador de porcelana, observa-se que este apresentou um valor $8 \%$ inferior ao traço de referência

Zhong e Wille (2015) realizaram estudos no concreto permeável com adição de um resíduo e observaram resultados da resistência à compressão de 14,6 MPa a 65,8 MPa em concretos permeáveis com porosidade variando entre 19,8\% a 30,2\%. Diante desse contexto, esta pesquisa busca investigar as propriedades físicas e mecânicas do concreto permeável com agregados de resíduos de isolador elétrico de porcelana verificando a viabilidade de uso deles.

\section{Metodologia}

$\mathrm{O}$ agregado graúdo tradicional escolhido possui a granulometria equivalente a brita 1 de origem ígnea, rocha de granitos, e o cimento utilizado se classifica como Cimento Portland composto com escória granulada de alto forno (CPII-E), com classe de resistência $32 \mathrm{Mpa}$, não será utilizado agregados miúdos devido as características da composição do concreto permeável. O cimento empregado e a sua composição granulométrica foram realizadas de acordo com os procedimentos descritos através da norma: NBR NM 248 (2003) e sua massa específica de acordo com a norma da ABNT NBR 16605 (2017).

Os isoladores elétricos de porcelana foram disponibilizados pela empresa PS Soluções, que trabalham na produção de bancos de capacitores. Eles foram cominuídos, a fim de obter uma granulometria similar a brita 1, devido o objetivo de substituir em porcentagens de $10 \%$ e $30 \%$ do agregado graúdo. A granulometria do agregado graúdo seguiu os procedimentos escritos na NBR NM 248 (2003) e para determinar a sua massa específica e do isolador de porcelana foi utilizada a norma ABNT NBR NM 53 (2009). Realizada a etapa de caracterização dos materiais quanto as características necessárias para o 
cálculo do traço, por se tratar de um concreto não convencional, optou-se por uma pesquisa bibliográfica para a determinação do traço, baseado em experimentos que obtiveram melhores resultados quanto a resistência a compressão axial, tendo em vista que o cálculo pelo método da Associação Brasileira de Cimento Portland foi desenvolvido para concretos convencionais e portanto não se aplica ao concreto em análise. Portanto, para determinar o traço, trabalhos anteriores que apontam que as maiores resistências são obtidas a partir das composições 1:4 e 1:3 (cimento: agregado). Segundo a ACI - 522R-06 (2006), os concretos permeáveis devem ser proporcionados com uma relação água/ cimento relativamente baixa $(0,30$ a 0,40$)$, porque uma quantidade excessiva de água levará à drenagem da pasta e subsequente fechamento do sistema de poros. A adição de água, portanto, tem que ser monitorada de perto no campo. Portanto, baseado em estudos anteriores e na norma ACI 522R:06 (2006), foi adotado uma relação de 1:4 (cimento: agregado) e uma relação água/cimento de 0,32.

Para a realização das moldagens dos corpos de prova foram adaptados os procedimentos descritos na norma ABNT NBR 5738 Versão Corrigida (2016) e ACI - 522R-06 (2006). Os cilindros e aformas retangular foram untados com uma fina camada de óleo, a fim de facilitar a retirada dos corpos de prova e evitar que houvesse algum dano físico no concreto. Para inserir o concreto nos cilindros, foram necessárias 3 camadas de concreto e em cada parcela no qual foram submetidos a compactação através de um bastão de madeira, a fim de criar uma forte ligação entre a pasta. Com o desmolde realizado, os corpos de prova foram identificados com um giz de cera e armazenados em um tanque de água e hidróxido de cálcio, para cura submersa, este procedimento evita a evaporação prematura da água necessária para a hidratação do cimento, a fim de que o concreto alcance suas características desejadas.

Mesmo com a inserção correta da massa de concreto nos cilindros, os corpos de prova apresentaram um pequeno desnivelamento, sendo necessário a realização do capeamento nas duas faces, onde a massa adicionada não ultrapassou $3 \mathrm{~mm}$ de espessura. Assim, após a cura, os corpos de prova de concreto estavam prontos para o teste de compressão, pois a carga inserida em sua face foi devidamente distribuída.

As porcentagens de substituição do agregado graúdo pelo isolador de porcelana foram de $10 \%$ e $30 \%$, a fim de se analisar o comportamento do concreto no ensaio de compressão axial. Considerando-se que o processo de cominuíção do isolador de porcelana seria manual, ficou definido que para a realização dos testes de compressão axial foram utilizadas as formas cilíndricas com $10 \mathrm{~cm}$ de diâmetro e $15 \mathrm{~cm}$ de altura.

Para a realização dos testes de determinação do índice de vazios, as formas cilíndricas utilizadas foram de $15 \mathrm{~cm}$ de diâmetro e $30 \mathrm{~cm}$ de altura e para determinação do coeficiente de permeabilidade, as formas retangulares foram utilizadas com $60 \mathrm{~cm}$ de largura, $60 \mathrm{~cm}$ de comprimento e $20 \mathrm{~cm}$ de altura, sendo que seria preenchido com concreto até a altura de $10 \mathrm{~cm}$.

Após a confecção dos corpos de prova foram efetuados testes de compressão axial conforme os procedimentos que constam na norma ABNT NBR 5739 (2018), a determinação do coeficiente de permeabilidade das amostras do concreto permeável foi identificada conforme o método de ensaio baseado na ASTM C1701 (2015) e obtido através da Lei de Darcy obtido através de um intervalo de tempo entre adição da água e seu desaparecimento de 20 segundos para o concreto referencial, 21 segundos para o concreto com $10 \%$ de isolador e 21 segundos para o concreto com $30 \%$ de isolador. A determinação do índice de vazios foi identificada conforme a norma ABNT NBR 9778 (2005) e para se obter o módulo de elasticidade do concreto, os procedimentos foram seguidos conforme a norma ABNT NBR 6118 (2014).

\section{Resultados e Discussão}

O Quadro 1 mostra os valores da composição granulométrica do agregado graúdo. No quadro 1 observou-se que o diâmetro das partículas está incluído na faixa de brita 1 com diâmetro máximo de 19,10 mm, pois está relacionado a grandeza associada à distribuição granulométrica do agregado, correspondente à abertura de malha quadrada, em mm, à qual corresponde uma porcentagem retida acumulada igual ou imediatamente inferior a 5\%. Os resultados demonstram que há uma 
maior quantidade, em porcentagem, ou seja, de massa retida de grãos na peneira com abertura de 9,52 $\mathrm{mm}$. Segundo Botteon (2017) utilizando uma dimensão do agregado graúdo uniforme, consegui aumentar o grau de permeabilidade do concreto.

O concreto permeável com agregado graúdo de diâmetro máximo característico $19 \mathrm{~mm}$ (Brita 1) produz vantagem hidrológica porque apresenta poros de maiores tamanhos e maior permeabilidade, menor retração e fissuração inicial que o de diâmetro máximo característico de 9,5 mm (Brita 0), entretanto possui menor resistência a compressão porque tem menor área de superfície de contato interno entre o agregado e a pasta de cimento (Yang \& Jiang, 2003).

Quadro 1. Granulometria do agregado graúdo.

\begin{tabular}{|c|c|c|c|c|}
\hline Peneiras abertura(mm) & Massa retida(gramas) & $\begin{array}{l}\% \\
\text { retida }\end{array}$ & $\begin{array}{l}\% \text { retida } \\
\text { acumulada }\end{array}$ & $\%$ Passante \\
\hline 31,5 & 0 & 0 & 0 & 100 \\
\hline 25,4 & 0 & 0 & 0 & 100 \\
\hline 19,1 & 0 & 0 & 0 & 100 \\
\hline 12,5 & 2474 & 45,08 & 45,08 & 54,92 \\
\hline 9,52 & 2560 & 46,63 & 91,71 & 8,29 \\
\hline 4,8 & 415 & 7,56 & 99,27 & 0,73 \\
\hline Fundo & 40 & 0,73 & 100,00 & 0,00 \\
\hline Massa Total (g) & \multicolumn{4}{|c|}{5490} \\
\hline Diâmetro Máximo (mm) & \multicolumn{4}{|c|}{19,10} \\
\hline Módulo de Finura & \multicolumn{4}{|c|}{2,36} \\
\hline Massa Específica $\left(\mathrm{g} / \mathrm{cm}^{3}\right)$ & \multicolumn{4}{|c|}{2,74} \\
\hline
\end{tabular}

Fonte: Autores (2021).

O Quadro 2 mostra os valores da composição granulométrica do isolador de porcelana. Para a determinação da granulometria do isolador de porcelana de acordo com a norma já citada, é definido o seu diâmetro máximo, onde ele é determinado de acordo com a abertura da peneira que apresentar uma porcentagem retida acumulada, inferior ou igual, a 5\% em massa, da mesma maneira executada pela brita, pois, os isoladores de porcelana foram cominuídos a fim de apresentarem, da forma mais parecida possível, as dimensões da brita. Sendo assim, de acordo com as médias das amostras estudas, obteve-se o Dmáx de 19,1 mm. Comparando a granulometria da brita em relação ao isolador de porcelana, pode-se observar que a brita apresenta uma distribuição granulométrica similar ao isolador de porcelana. 
Quadro 2. Granulometria do isolador de porcelana como agregado graúdo.

\begin{tabular}{|c|c|c|c|c|}
\hline Peneiras abertura(mm) & Massa retida(gramas) & $\%$ retida & $\%$ retida acumulada & $\%$ Passa \\
\hline 31,5 & 0 & 0 & 0 & 100 \\
\hline 25,4 & 0 & 0 & 0 & 100 \\
\hline 19,1 & 260 & 4,74 & 4,74 & 95,26 \\
\hline 12,5 & 2900 & 52,82 & 57,56 & 42,44 \\
\hline 9,52 & 1615 & 29,42 & 86,97 & 13,03 \\
\hline 4,8 & 615 & 11,20 & 98,18 & 1,82 \\
\hline Fundo & 100 & 1,82 & 99,99 & 0,01 \\
\hline Total & \multicolumn{4}{|c|}{5490} \\
\hline Diâmetro Máximo (mm) & \multicolumn{4}{|c|}{19,10} \\
\hline Módulo de Finura & \multicolumn{4}{|c|}{2,47} \\
\hline Massa Específica $\left(\mathrm{g} / \mathrm{cm}^{3}\right)$ & \multicolumn{4}{|c|}{2,36} \\
\hline
\end{tabular}

Fonte: Autores (2021).

A Figura 1 mostra os resultados encontrados para a resistência à compressão axial do concreto permeável aos 14 e 28 dias, indicando os valores individuais de resistência a compressão axial de cada corpo de prova. Através dos resultados, observou-se que a 14 dias a resistência a compressão aumentou de $(6,35 \pm 0,45) \mathrm{MPa}$ da amostra referencial para $(10,35 \pm 0,46) \mathrm{MPa}$ da amostra com $30 \%$. Aos 28 dias, a resistência à compressão do concreto aumentou de $(8,06 \pm 0,55) \mathrm{MPa}$ na amostra referencial para $(10,33 \pm 1,07)$ da amostra com $30 \%$. Zaetang (2016) verificou que a substituição parcial do agregado por resíduo promove um aumento na resistência à compressão do concreto permeável. A adição de outros materiais suplementares, poliméricos, fibras ou cerâmico podem também melhorar algumas características do concreto. Tais adições têm como objetivo melhorar a resistência de ligação dos agregados, sem prejudicar os vazios permeáveis.

Também observou que os valores da resistência a compressão aumentaram no concreto referencial e $10 \%$, entretanto não houve alterações nos seus valores ao 30\% para a idade de 14 dias para 28 dias.

Ao analisar os resultados podemos atribuir esse aumento a resistência acompressão aos isoladores de porcelanas que são constituídos de material cerâmico, produzido a frio e submetido a um extenso processo de secagem a altas temperaturas. Esses isoladores são materiais extremamente rígidos, apresentando alta resistência a compressão, resistência à ataques químicos, elevado ponto de fusão (Campos, 2011).

Botteon (2017) e Batezini (2013) constataram que o concreto permeável se mostra menos resistente que o concreto tradicional, apresentando valores de resistência à compressão axial variando de 4 a $28 \mathrm{MPa}$.

Segundo Holtz (2011), o concreto permeável geralmente apresenta uma resistência à compressão na faixa de 3,5 a $28 \mathrm{MPa}$. Devido à ausência de finos, a resistência à compressão de um concreto permeável tende a ser inferior à de um concreto convencional (Ribeiro, Werdine, Barbosa, Oliveira E Santana, 2021). As tensões máximas de compressão suportadas por uma mistura do concreto permeável dependem do tamanho e distribuição dos grãos, da porosidade comunicante e o tipo e quantidade de aditivos usados. 
Figura 1. Resistência à compressão axial do concreto permeável a 14 e 28 dias.

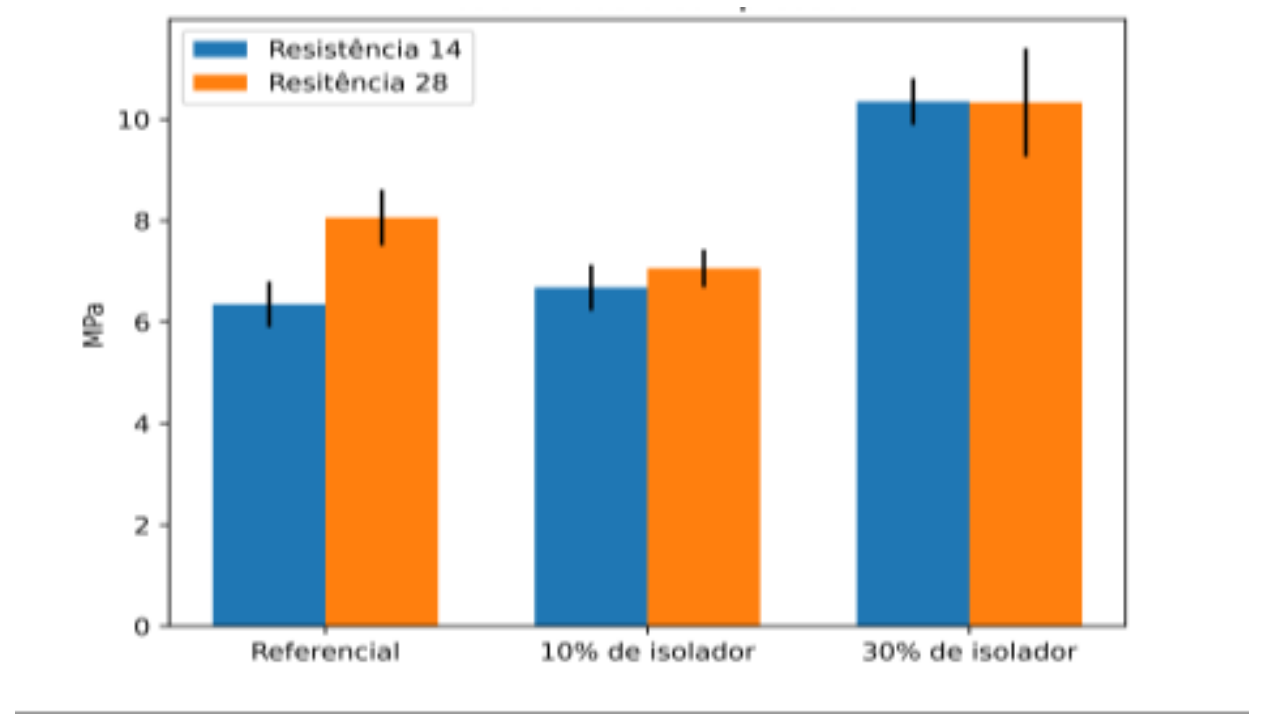

Fonte: Autores (2021).

A Figura 2 mostra os resultados encontrados para o módulo de elasticidade do concreto aos 14 e 28 dias. Através dos resultados, observou-se que a 14 dias o módulo de elasticidade aumentou de $(14,11 \pm 1,25)$ MPa da amostra referencial para $(18,02 \pm 1,25) \mathrm{MPa}$ da amostra com 30\%. Aos 28 dias, o módulo de elasticidade do concreto aumentou de $(15,89 \pm 0,88)$ MPa na amostra referencial para $(17,99 \pm 0,88)$ da amostra com 30\%. Os valores do módulo de elasticidade também aumentaram do concreto referencial e $10 \%$ para a idade de 14 dias para 28 dias, entretanto não houve alterações nos seus valores ao $30 \%$.

Os valores do módulo de elasticidade podem ser atribuídos à natureza rígida, maior dureza dos resíduos de isoladores cerâmicos, fruto de sua composição química e sua baixa porosidade (Zimmermann E Zattera, 2013). Com base nestas análises é importante salientar que o tipo de resíduo empregado no concreto como agregado, e suas características, influenciaram na propriedade analisada.

Figura 2. Módulo de elasticidade do concreto permeável a 14 e 28 dias.

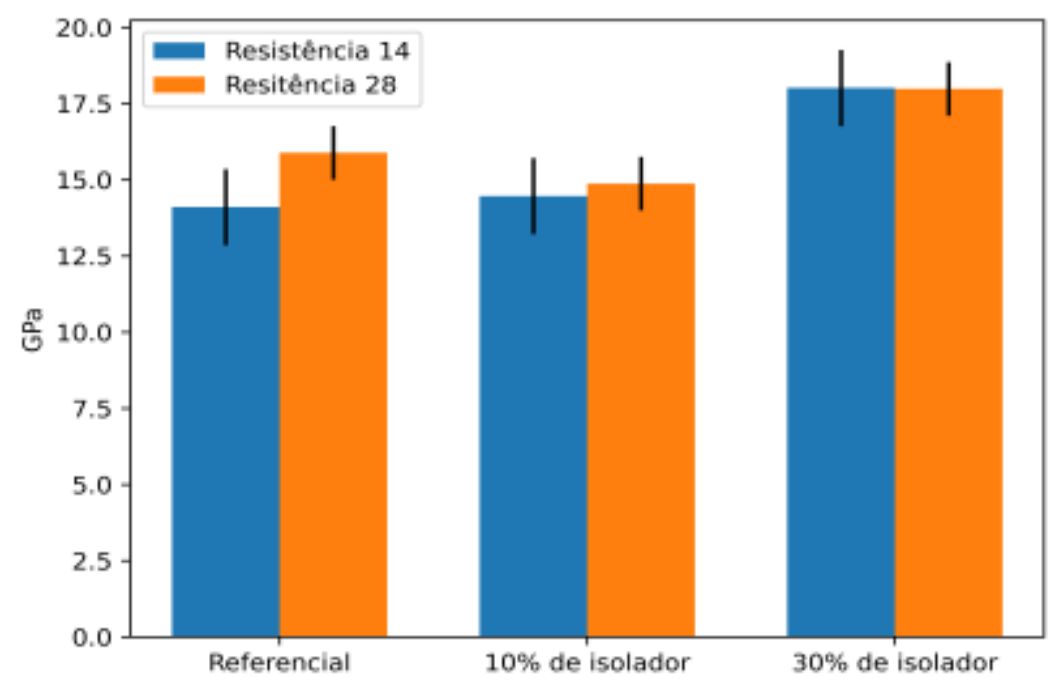

Fonte: Autores (2021). 
A Figura 3 mostra os resultados encontrados para o índice de vazios do concreto aos 14 e 28 dias. Através dos resultados, observou-se que aos 14 dias o índice de vazios aumentou de $(9,56 \pm 0,68)$ MPa na amostra referencial para $(11,89 \pm 0,68) \mathrm{MPa}$ da amostra com $30 \%$. Aos 28 dias, o índice de vazios aumentou de $(12,59 \pm 0,04)$ MPa na amostra referencial para $(13,82 \pm 0,25)$ da amostra com $30 \%$.

O crescimento do índice de vazios ocorreu devido ao aumento da porcentagem de isolador de porcelana no concreto. Nota-se o resultado do índice de vazio do concreto com $30 \%$ de isolador foi o que mais se aproximou, contudo não atingiu a porcentagem de índice de vazios que caracterizam os concretos permeáveis. Segundo Batezini e Balbo (2013), o compósito é denominado de baixa porosidade quando seu índice de vazios é inferior a 15\%; entretanto um índice de vazios superior a 30\%, descreve um material altamente poroso.

Segundo Rizvi, Henderson e Norris (2010), valores muito acima de 30\% ocasionariam níveis muito inferiores da resistência a compressão. Embora os autores divirjam acerca do limite superior desse parâmetro, todos confluem quanto à necessidade da busca por um valor ótimo que garanta concomitantemente boas características de resistência e permeabilidade. (Tennis, Leming E Akers, 2004) testificam que os índices de vazios ideais para que concretos dessa espécie alcancem padrões aceitáveis de ambas as propriedades giram em torno de $20 \%$.

Segundo Bechara (2017), os vazios apresentados pelos concretos porosos devem observar o intervalo de $15 \%$ a $25 \%$, sendo essa faixa considerada a ideal para equalizar as características drenantes às resistências mecânicas mínimas de trabalho.

Figura 3. Índice de vazios do concreto permeável a 14 e 28 dias.

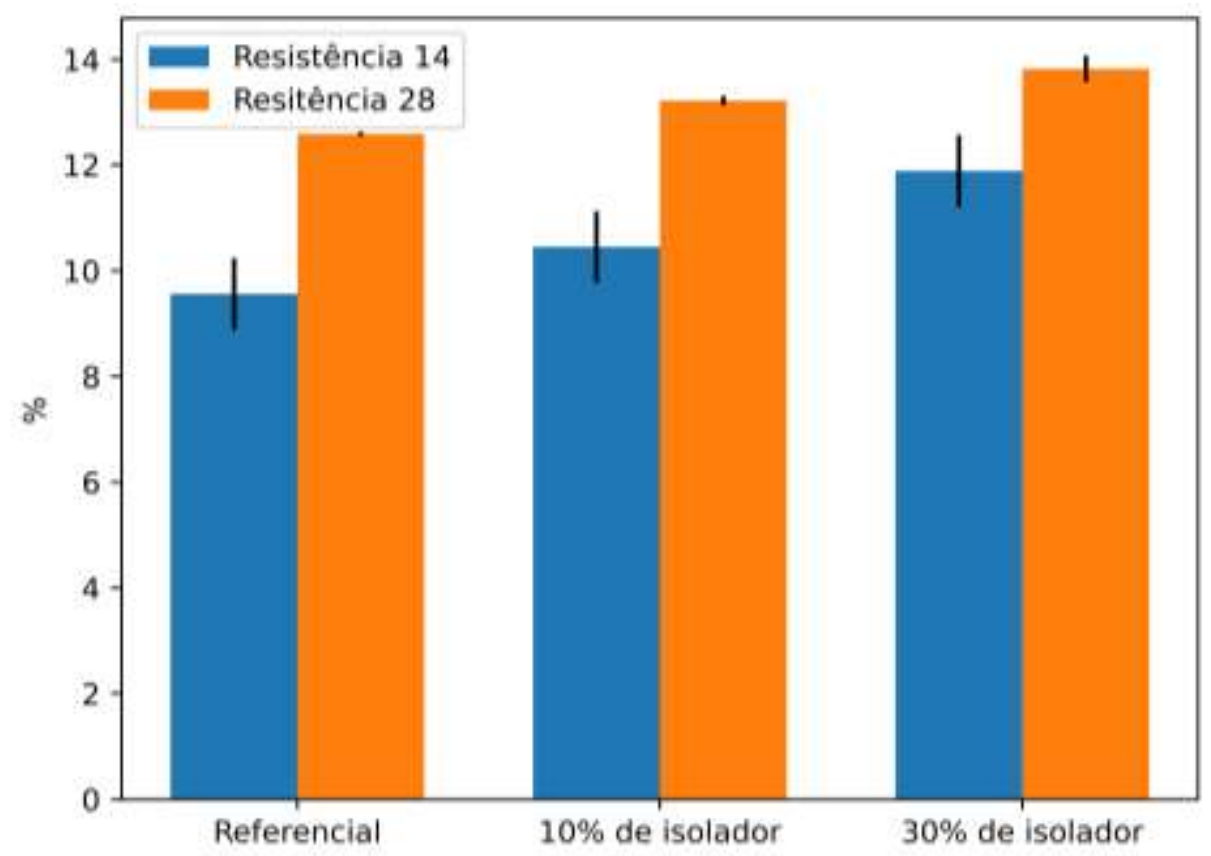

Fonte: Autores (2021).

A Figura 4 mostra os resultados obtidos do coeficiente de permeabilidade do concreto permeável. Através da Lei de Darcy observou-se que o coeficiente de permeabilidade do concreto referencial diminuiu de 4583,66 mm/h, para $4365,39 \mathrm{~mm} / \mathrm{h}$ para o concreto com $10 \%$ de isolador. Entretanto, verificou-se que não houve diferença significativa no coeficiente de permeabilidade dos concretos com $10 \%$ e 30\%. Transformando os valores do coeficiente de 
permeabilidade de $\mathrm{mm} / \mathrm{h}$ para $\mathrm{m} / \mathrm{s}$ obtemos os seguintes valores: $1,27 \times 10^{-3} \mathrm{~m} / \mathrm{spara}$ o concreto referencial e $1,21 \times 10^{-3}$ $\mathrm{m} / \mathrm{s}$ para o concreto com $10 \%$ e 30\%. Segundo Faria, Santana, Barbosa e Donato (2019), o coeficiente de permeabilidade depende essencialmente da temperatura, granulometria e do índice de vazios. Quanto maior for a temperatura, menor é a viscosidade da água e, portanto, ela consegue tem um melhor escoamento entre os vazios e consequentemente aumenta o coeficiente de permeabilidade.

Através da análise dos dados é possível perceber que todos os traços apresentaram muita permeabilidade, ultrapassando o limite mínimo estabelecido pela ABNT NBR 16416 (2015) que é de $10^{-3} \mathrm{~m} / \mathrm{s}$, quanto menor esse valor menos permeável é o solo. Comparando os valores utilizados na pavimentação e possuem um grau de permeabilidade entre $10^{-7} \mathrm{~m} / \mathrm{s}$ e $10^{-9} \mathrm{~m} / \mathrm{s}$, extraídos a partir dos valores típicos do coeficiente de permeabilidade da ACI - 522R-06 (2006) caracteriza-se como "muito baixo grau de permeabilidade".

Figura 4. Coeficiente de permeabilidade do concreto permeável.

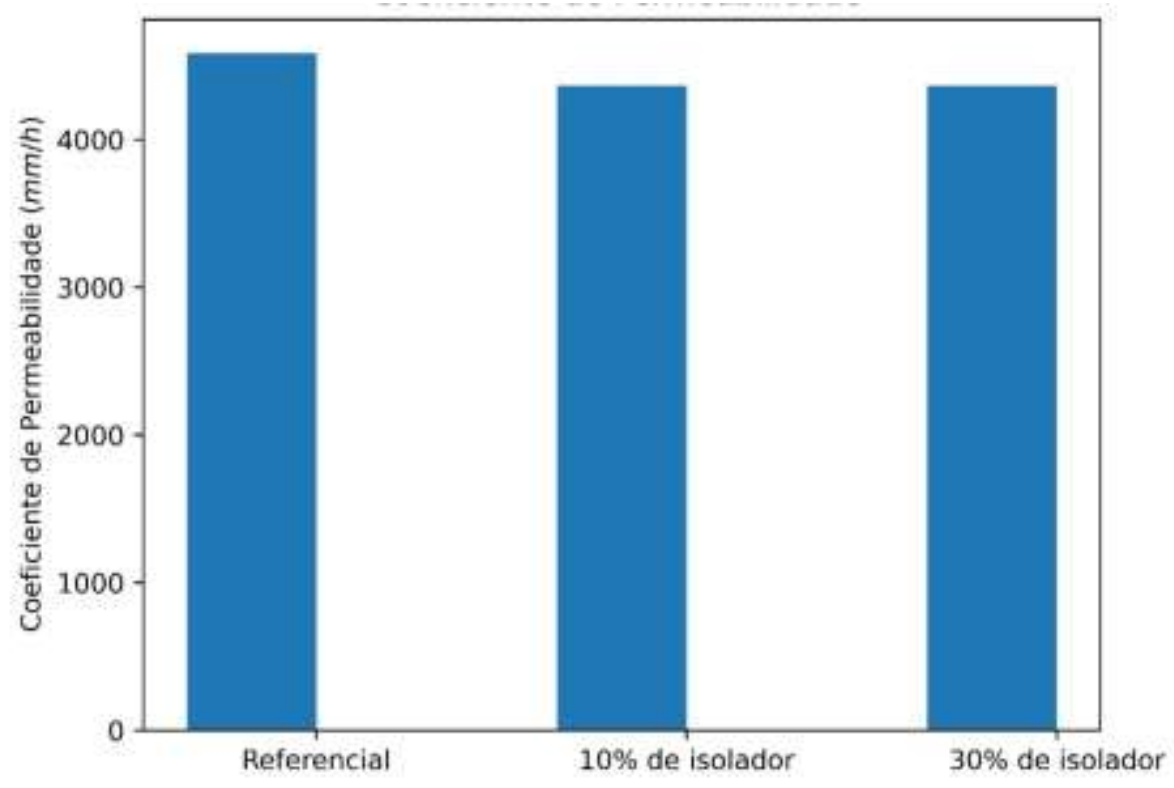

Fonte: Autores (2021).

Um fator negativo que está intimamente ligado com a taxa de permeabilidade é a colmatação que ocorre naturalmente com o passar do tempo nestes pavimentos. Colmatação é o entupimento dos poros permeáveis por sujeira, poeira, restos vegetais ou detritos podendo ocorrer de maneira rápida ou não, dependendo de vários fatores externos, como muita vegetação nas proximidades ou risco grande de carreamento destes resíduos na estrutura porosa. Concretos mais porosos, com mais índices de vazios demoram mais para colmatar quando comparados a concretos pouco porosos em mesmas condições de uso. Com isto, percebe-se que a porosidade deve ser controlada de acordo com a necessidade de resistência e permeabilidade de projeto (Silva, et al., 2019). As amostras produzidas não atenderam ao requisito normativo (NBR 16416- tabela 8) de resistência à compressão de 20-35 MPa.

\section{Conclusão}

A geração de resíduos, em geral, pode trazer diversos problemas ao meio ambiente em decorrência de seu descarte 
inadequado, tornando necessária a busca por métodos alternativos para o manuseio, tratamento e disposição final deles. Sendo assim este estudo buscou produzir e caracterizar concretos permeáveis com o emprego de resíduos de isoladores elétricos de porcelana, cominuídos, em substituição a matérias-primas de fontes não renováveis e compará-lo com o concreto permeável elaborado com agregado graúdo convencional, analisando através de ensaios a viabilidade dessa substituição.

Com relação as características mecânicas analisadas, o concreto com $30 \%$ de substituição de brita por resíduos de isoladores elétricos de porcelana, apresentou o melhor resultado entre as substituições analisadas da resistência a compressão axial, sendo este resultado maior que a resistência do concreto permeável elaborado com agregado graúdo convencional, o que representa um aumento de $28,41 \%$ de resistência a compressão axial.

Através dos resultados, observou-se que a 14 dias a resistência a compressão, módulo de elasticidade e índice de vazios aumentaram da amostra referencial para da amostra com 30\%. Aos 28 dias, a resistência à compressão, módulo de elasticidade e índice de vazios aumentaram na amostra referencial para amostra com $30 \%$.

Através da Lei de Darcy observou-se que o coeficiente de permeabilidade do concreto referencial diminuiu para o concreto com $10 \%$ de isolador. Entretanto, verificou-se que não houve diferença significativa no coeficiente de permeabilidade dos concretos com $10 \%$ e $30 \%$.

As amostras produzidas não atenderam ao requisito normativo (NBR 16416- tabela 8) de resistência à compressão de 20-35 MPa.

Os resultados demonstram que existe um grande potencial para a utilização de resíduos reciclados de isoladores elétricos de porcelana em substituição a agregados graúdos. Com base no desenvolvimento deste estudo e seu tema, são sugeridos os seguintes temas para trabalhos futuros: Avaliar a durabilidade de concretos permeáveis com adição de resíduos de isolador elétrico de porcelana, estudar os efeitos de colmatação; verificar a influência da granulometria nas propriedades do concreto permeável, estudar a influência da microestrutura nas propriedades do concreto permeável com isolador elétrico de porcelana.

\section{Referências}

Milhomem, P. M., da Silva, J. M., \& Costa, P. S. (2018). Avaliação das propriedades mecânicas do concreto produzido com resíduo de isoladores elétricos de porcelana. Revista Eletrônica da Engenharia Civil, 14(1), 238-247.

ABNT NBR 16416, A. B. (2015). Pavimentos permeáveis de concreto - Requisitos e procedimentos.

ABNT NBR 16605, A. B. (2017). Cimento Portland e outros materiais em pó - Determinação da massa específica.

ABNT NBR 5738 Versão Corrigida:2016, A. B. (2015). Concreto - Procedimento para moldagem e cura de corpos de prova.

ABNT NBR 5739, A. B. (2018). Concreto - Ensaios de compressão de corpos-de-prova cilíndricos.

ABNT NBR 6118, A. B. (2014). Projeto de estruturas de concreto - Procedimento.

ABNT NBR 9778, A. B. (2005). Argamassa e concreto endurecidos - Determinação da absorção de água por imersão - Índice de vazios e massa específica Método de ensaio. Rio de Janeiro.

ABNT NBR NM 53, A. B. (2009). Agregado graúdo - Determinação de massa específica, massa específica aparente e absorção de água. Rio de Janeiro. ACI - 522R-06, A. C. (2006). Pervious Concrete.

ASTM C1701, A. S. (2015). Standard Test Method for Infiltration Rate of In Place Pervious Concrete.

Batezini, R., \& Balbo, J. B. (2013). Estudo preliminar de concretos permeáveis como revestimento de pavimentos para áreas de veículos leves. Revista Ibracon Estrut. Materiais, 8(3).

Batezinij, R. .. (2015). Estudo da condutividade hidráulica com carga constante e variável em concretos permeáveis. Rev. IBRACON Estrut. Mater, 8(3).

Bechara, L. A. (2017). "Concreto permeávelcomo revestimento de pavimento permeável: alternativa de drenagem urbana não estrutural à região metropolitana de Belém. Dissertação de Mestrado, Universidade Federal do Pará.

Botelho, D. N., \& Aguado, R. A. (2020). Concreto permeável: análise de desempenho voltada para pavimentação, a fim de combater inundações em centros urbanos. Braz. J. of Development, 18300-18320. 
Research, Society and Development, v. 10, n. 8, e23610817286, 2021

(CC BY 4.0) | ISSN 2525-3409 | DOI: htttp://dx.doi.org/10.33448/rsd-v10i8.17286

Botteon, L. M. (2017). Desenvolvimento e Caracterização de Concreto Permeável para Utilização em Blocos Intertravados para Estacionamentos. Trabalho de Conclusão de curso, Universidade Federal Fluminense.

Campos, M. A. (2011). Análise microestrutural e das propriedades mecânicas e de durabilidade de argamassas e concretos com isoladores elétricos de porcelana. Faculdade de Engenharia Civil, Arquitetura e Urbanismo, Universidade Estadual de Campinas, Campinas.

Cardoso, E. B., Shimosaka, T. H., Filho, M. P., \& Paulazzi, M. (2017). Obtenção de Concreto Permeável produzido com Agregado. Congresso Técnico Científico da Engenharia e da Agronomia.

Carvalho, S. A., \& Aquino, S. R. (2017). O Modelo de Decrescimento, Crescimento e Desenvolvimento Sustentável. Revista FSA, 14(1), 79-105,.

Commilttee, A. 5.-0. (2006). Pervious Concrete.

Faria, A. C., Santana, J. G., Barbosa, J. M., \& Donato, M. (2019). Pavimento de concreto drenante: estudo da granulometria que favorece a drenagem e que afete o mínimo na resistência.

Ferrão, P. A., \& Costa, I. (2010). Journal of Cleaner Production, 18, 984-992.

Holtz, F. C. (2011). "Uso de concreto permeável na drenagem urbana: análise da viabilidade técnica e do impacto ambiental. Dissertação de Mestrado, , Universidade Federal do Rio Grande do Sul.

Li, J. M. (2009). Design of Previous Recycled Concrete. Geohunan International Conference - Material Design Construction, Maintenance, and Testinf of paviments, 195(15), 103-108.

NBR 16416, A. B. (2015). Pavimentos permeáveis de concreto - Requisitos e procedimentos.

NBR NM 248, A. B. (2003). Agregados - Determinação da composição granulométrica.

Ribeiro, V. A., Werdine, D., Barbosa, L. F., Oliveira, A. F., \& Santana, L. P. (2021). Investigation of the properties of conventional concrete with addition of waste tire and metakaolin. Research, Society and Development, 10(5).

Rizvi, R. T., Henderson, V., \& Norris, J. (2010). Evaluating the Use of Recycled Concrete Aggregate in Pervious Concrete Pavement. Transportation Research Record: Journal of the Transportation Research Board, 2164, 132-140.

Silva, R. G., Bortoletto, M., Spósito, F. A., Bigotto, S. A., Assunção, C. C., \& Albuquerque, M. C. (2019). Concreto permeável: principais características e aplicação em pavimentação. Anap Brasil Revista Científica, 12(26), 2-11.

Tennis, P. D., Leming, M., \& Akers, D. (2004). EB302, pervious concrete pavements.

Yang, J., \& Jiang, G. (2003). Experimental study on properties of pervious concrete pavement materials,. Cement and Concrete Research, 33, 381-386.

Zaetang, Y. S. (2016). Properties of pervious concrete containing recycled concrete block aggregate and recycled concrete aggregate. Construction and Building Materials, 111, 15-21.

Zhong, R., \& Wille, K. (2015). Material design and characterization of high performance pervious concrete. Construction And Building Materials, 98, 51-60,.

Zimmermann, M. V., \& Zattera, A. J. (2013). Recycling and reuse of waste from electricity distribution networks as reinforcement agents in polymeric composites. Waste Management, 33(7), 1667-1674. 